\title{
COVID-19 and the Kidneys: Risk, Damage and Sequelae
}

\author{
Raúl Herrera-Valdés MD MS PhD DSc, Miguel Almaguer-López MD MS, Laura López-Marín MD MS, Raymed Bacallao-Méndez MD MS, \\ Jorge F. Pérez-Oliva MD MS PhD, Guillermo Guerra-Bustillo MD MS
}

At first, COVID-19 was thought to be primarily a respiratory disease, progressing in some patients to serious respiratory symptoms, pneumonia, severe respiratory distress syndrome and even death. Later analysis revealed entire systems were compromised, affecting other vital organs, including the kidneys, and a correlation was observed between chronic kidney disease (CKD) and COVID-19 severity.[1,2]

This correlation can be broken down into three underlying circumstances: 1) CKD as a risk factor for infection, particularly in patients with end-stage renal disease (ESRD) who are either in dialysis or have received a transplant; 2) persons in the active stages of SARS-CoV-2 infection whose healthy kidneys develop lesions, including acute kidney injury (AKI); and 3) the possibility of medium- and long-term renal sequelae.

Conditions such as hypertension, cardiovascular disease, diabetes, advanced age, chronic obstructive pulmonary disease, obesity and CKD are associated with greater risk of COVID-19 and more severe infection. All these factors are often present in persons with CKD: for starters, diabetes and hypertension are the main drivers of CKD, and then the rest of the conditions are habitual comorbidities. Convergence of these factors not only increases risk, but their synergy facilitates chronic inflammation and the ensuing cytokine buildup. In advanced CKD, other comorbidities crop up, such as anemia, malnutrition, vitamin $D$ deficiency, immunodepression and the effects of immunosuppressors that accompany autoimmune diseases or renal transplant therapies.

In 2019, 4.37 million patients were receiving renal replacement therapies (RRT) worldwide. For hemodialysis patients, this implies the challenge of guaranteeing their frequent transportation to closed facilities with specialized personnel and equipment. For those with COVID-19, it has also meant setting aside dialysis units, patient circuit kits, medicines and staff to be deployed in isolation areas, given the attendant high risk to other RRT patients. Additionally, as health systems become saturated with the pandemic, transplants are postponed with few exceptions (such as combined organ transplants, emergency life-and-death situations, or when there is an optimal kidney available for a patient with few other options).[3]

Kidney damage is frequent during the active stage of COVID-19. A meta-analysis in China involving 4375 patients revealed high relative rates of proteinuria (42.0\%), hematuria (30.3\%) and AKI $(7.7 \%)$, as well as elevated creatinine (6.6\%) and urea (6.2\%). [4] Also in China, higher mortality was reported for COVID-19 patients with renal damage $(11.2 \% ; 28 / 251)$ than for those without (1.2\%; 1/82).[5] A prospective study of 1603 patients in Spain obtained similar results.[6] A US study of 5449 COVID-19 patients revealed hematuria and proteinuria in 46\%, AKI in 37\%, and dialysis required for 15\%.[7] Over $40 \%$ of ICU patients required $\mathrm{RRT}$.

In China, post-mortem studies confirmed lesions in the proximal tubules of the kidneys: loss of the brush border, vacuolar degen- eration, lumen dilation with associated buildup of cellular debris, denudation of the epithelium, erythrocyte aggregation, severe acute tubular necrosis, and interstitial lymphocyte infiltration. Additionally, they observed obstruction of the glomular and peritubular capillaries, and thrombi composed of aggregated platelets and fibrin.[8] Immunohistochemical analysis of the tubules showed an increase in the receptor for angiotensin converting enzyme 2 (ACE2) as well as antibodies against the nucleoprotein of SARS-CoV-2. Viral invasion was also detected elsewhere in kidney tissue. Electron microscopy and tests with anti-SARSCoV-2 antibodies show the direct cytopathic effects of viral replication in kidney tubular cells and in podocytes.[9]

Symptomatic COVID-19 patients exhibit a cytokine buildup and decreased $T$ lymphocytes. The most severe cases present with a 'cytokine storm'-interleukin-6, IL-6; interleukin-2 receptor, IL-2R; interleukin-10, IL-10; and tumor necrosis factor alpha,TNF- $\alpha$-as well as decreased interferon gamma (IFN- $\gamma$ ), which are associated with lung damage and respiratory distress. All these are conducive to kidney injury and imply a poor prognosis.[10]

The marked expression of ACE2 receptors in podocytes and proximal tubules suggests that the kidney may be an important target organ for SARS-CoV-2, because the virus invades cells by binding to such ACE2 receptors, subsequently inducing a decrease in the ACE2 enzyme. ACE2 belongs to the reninangiotensin-aldosterone system (RAAS). Angiotensin II (Ang II) is one of the main mediators of damage in kidney diseases, and the activation of RAAS has a strong influence on kidney disease progression. This system maintains a functional balance between ACE and ACE2; the first promoting the formation of Ang II, with vasoconstrictive, mitotic, inflammatory and fibrotic effects.

The main function of ACE2 is catabolism of Ang II to produce angiotensin 1-7. Angiotensin 1-7 reduces vasoconstriction, salt retention, oxidative stress and cell proliferation as a consequence of increased nitrous oxide and prostaglandins. The decrease in ACE2 promotes accumulation of Ang II by reducing its degradation to angiotensin 1-7, resulting in an imbalance of RAAS components with accumulation of Ang II. Decreased ACE2 and increased ACE indicate response to kidney damage progression. $[11,12]$

In terms of COVID-19 pathophysiology, WHO and PAHO have confirmed that the disease generates an inflammatory response that primarily affects the lungs, provoking sequelae in the cardiovascular, central nervous and peripheral nervous systems, as well as psychiatric and psychological sequelae.[13] Nevertheless, they have not mentioned renal sequelae.

Here, we return to the ACE2 receptor, since it plays a role in the mechanism by which SARS-CoV-2 damages the respiratory tract as its primary target, possibly propagating via the bloodstream to damage cells of other organs. Kidneys are the body's most vascularized organs, with 180 liters of blood circulating through them daily, and are one of the organs with greater ACE2 content, along 


\section{Viewpoint}

with the small intestine, testicles and heart. Thus, they are at high risk when it comes to COVID-19.[14]

In addition to the virus's cytopathic effects, a number of other factors can contribute to renal lesions, including hemodynamic changes, cytokine liberation, coagulatory disorders, sepsis, systemic hypoxia, drug-related toxicity and rhabdomyelosysis.[15]

Medium- and long-term COVID-19 impact on the kidneys is unclear, as is whether surviving patients with AKI can recover full renal function. What is clear is that the kidneys are involved in COVID-19 infection and AKI is an independent predictor of mortality.[16]

It is probable that kidney lesions acquired during the disease's active remain as sequelae that may result in a slow and asymp- tomatic progression towards advanced stages and CKD. Thus, patients who have recovered from COVID-19 who presented proteinuria, hematuria, elevated creatinine and AKI should be monitored for CKD.

By 2017, over 850 million people were estimated to suffer from various stages of CKD and ARD worldwide, twice the number of diabetics and 20 times more than those with HIVIAIDS. Given the high numbers of COVID-19 cases globally, we foresee the possibility of millions more people who may require dialysis or transplant. But, is the world and its health systems-stretched to the limit as they are-prepared to face a chronic kidney disease pandemic superimposed or following the coronavirus pandemic? Not yet, certainly. And we can hardly afford to ignore the warnings of such an eventuality: we have already seen where that can lead, and too many have already paid the price with their lives. $-1 /$ -

\section{REFERENCES}

1. Yang $X, Y u Y, X u J$, Shu $H$, Xia J, Liu H, et al. Clinical course and outcomes of critically ill patients with SARS-CoV-2 pneumonia in Wuhan, China: a single-centered, retrospective, observational study. Lancet Respir Med. 2020 May;8(5):475-81.

2. Wang X, Fang X, Cai Z, Wu X, Gao X, Min J, et al. Comorbid chronic diseases and acute organ injuries are strongly correlated with disease severity and mortality among COVID-19 patients: a systemic review and meta-analysis. Research [Internet]. 2020 [cited 2020 Aug 10];2020: Article ID 2402961.,17 p. Available at: https://doi .org/10.34133/2020/2402961

3. Parson JA, Martin DE. A call for dialysis-specific resource allocation guidelines during COVID-19. Am J Bioethics. 2020 Jul 27 [cited 2020 Aug 10];20(7):199-201. Available at: https://doi.org/1 0.1080/15265161.2020.1777346

4. Yang $\mathrm{Q}$, Yang $\mathrm{X}$. Incidence and risk factors of kidney impairment on patients with COVID-19: a systematic review and meta-analysis. medRxiv [Internet]. New York: Cold Spring Harbor Laboratory; 2020 Jun 3 [cited 2020 Aug 11]. Available at: https://doi.org/10.1101/2020.05.28.20116400

5. Pei G, Zhang Z, Peng J, Liu L, Zhang C, Yu C, et al. Renal involvement and early prognosis in patients with COVID-19 pneumonia. JASN [Internet]. 2020 Jun [cited 2020 Aug 11];31(6):1157-65. Available at: https://doi.org/10.1681/ASN.2020 030276

6. Portolés J, Marques M, López-Sánchez P, Valdenuevo M, Muñez E, Serrano ML, et al. Chronic kidney disease and acute kidney injury in the COVID-19 Spanish outbreak. Nephrol
Dial Transplant. 2020 Sep 2 [cited 2020 Sep 4];35(8):1353-61. Available at: https://doi .org/10.1093/ndt/gfaa189

7. Hirsch JS, Ng JH, Ross DDW, Sharma P, Shah $\mathrm{HH}$, Barnett $\mathrm{RL}$, et al. Acute kidney injury in patients hospitalized with COVID-19. Kidney Int. 2020 Jul [cited 2020 Aug 11];98(1):209-18. Available at: https://doi.org/10.1016/j.kint.2020.05.006

8. Su H, Yang M, Wan C, Yi L, Fang Tang F, Zhu $\mathrm{H}$, et al. Renal histopathological analysis of 26 postmortem findings of patients with COVID-19 in China. Kidney Int. 2020 Jul 1 [cited 2020 Aug 11];98(1):219-27. Available at: https://doi .org/10.1016/j.kint.2020.04.003

9. Farkash EA, Wilson AM, Jentzen JM. Ultrastructural evidence for direct renal infection with SARS-CoV-2. JASN [Internet]. 2020 Aug [cited 2020 Aug 13];31(8):1683-7. Available at: https:// doi.org/10.1681/ASN.2020040432

10. Pedersen SF, Ho Y. SARS-CoV-2: a storm is raging. J Clin Invest. 2020 May 1 [cited 2020 Aug 13];130(5):2202-5. Available at: https://doi .org/10.1172/JCI137647

11. Mizuiri S, Ohashi Y. ACE and ACE2 in kidney disease. World J Nephrol. 2015 Feb 6;4(1):74-82. Available at: https://www.ncbi.nlm.nih.gov/pmc/ articles/pmid/25664248/

12. Gabarre $P$, Dumas $G$, Dupont $T$, Darmon $M$, Azoulay E, Zafrani L. Acute kidney injury in critically ill patients with COVID-19. Intensive Care Med. 2020 Jul [cited 2020 Aug 13];46(7):1339_ 48. Available at: https://link.springer.com/arti cle/10.1007/s00134-020-06153-9

13. Organización Panamericana de la Salud / Organización Mundial de la Salud. Alerta Epi- demiológica: COVID-19, complicaciones y secuelas. 12 de agosto de 2020 [Internet] Washington, D.C.: Pan American Health Organization; World Healt Organization; 2020 Aug 12 [cited 2020 Aug 13]. 17 p. Available at: https:// www.paho.org/es/documentos/alerta-epidemio logica-complicaciones-secuelas-por-covid -19-12-agosto-2020. Spanish.

14. Li M-Y, Li L, Zhang Y, Wang X-S. Expression of the SARS-CoV-2 cell receptor gene ACE2 in a wide variety of human tissues. Infect Dis Poverty. 2020 Apr 28 [cited 2020 Aug 13];9:45. Available at: https://doi.org/10.1186/s40249-020-00662-x

15. Batlle D, Soler MJ, Sparks MA, Hiremath S, South AM, Welling PA, et al. Acute kidney injury in COVID-19: emerging evidence of a distinct pathophysiology. J Am Soc Nephrol [Internet]. 2020 Jul [cited 2020 Aug 16];31(7):1380-3 Available at: https://jasn.asnjournals.org/con tent/31/7/1380.long

16. Naicker S, Yang C-W, Hwang S-J, Liu B-C, Chen $\mathrm{J}-\mathrm{H}$, Jha V. The Novel Coronavirus 2019 epidemic and kidneys. Kidney Int. 2020 May:97(5):8248. Available at: https://doi.org/10.1016/j.kint.2020 .03 .001

Submitted: September 13, 2020

Approved for publication: September 26, 2020 Disclosures: None

Correspondence: raul.herrera@infomed.sld.cu 